\title{
Mariposas de instantes: aspectos estilísticos y pragmáticos en los poemas sintéticos de José Juan Tablada.
}

\author{
Instant's butterflies: stylistic and pragmatic aspects in Jose Juan \\ Tablada's synthetic poems.
}

Esta obra está bajo una Licencia Creative Commons Atribución 4.0 Internacional. DOI: $10.32870 /$ sincronia.axxiii.n75.11a19

\author{
Manuel Alejandro González Palomares \\ Université Paul-Valéry Montpellier III \\ Institut de Recherche Intersite en Études Culturelles (IRIEC) \\ alexgonpal@gmail.com \\ (FRANCIA)
}

Recibido: $26 / 09 / 2018$

Revisado: $22 / 11 / 2018$

Aprobado: $11 / 12 / 2018$

\section{RESUMEN}

A un siglo de la publicación de Un día... Poemas sintéticos de José Juan Tablada en 1919, revisitamos desde el punto de vista de la pragmática de la literatura (principalmente de las ideas de Sperber y Wilson y Escandell Vidal) el concepto de "síntesis poética" propuesto por el autor y debatido en su época por Ramón López Velarde. Consideramos en este estudio que los Ilamados "haikús" de Tablada se desarrollaron en dos estilos diferenciables en sus aspectos retóricos-pragmáticos: un estilo maximalista y un estilo minimalista. Ambos estilos revelan una tensión constante que se halla en el seno de las ideas estéticas del poeta mexicano.

Palabras clave: Tablada. Haikú. Estilística. Pragmática. 


\begin{abstract}
A century after the publication of Un día... Poemas sintéticos by José Juan Tablada in 1919, we revisit the concept of "poetic synthesis" from a literary pragmatic standpoint (mainly the ideas of Sperber and Wilson and Escandell Vidal) which was proposed by the author and debated by Ramón López Velarde. We consider in this study that the so-called "haikus" of Tablada evolved into two styles in easily distinguishable by their rhetorical and pragmatic elements: a maximalist style and a minimalist style. Both styles reveal a persistent tension that lies within the aesthetic ideas of the Mexican poet.
\end{abstract}

Keywords: Tablada. Haiku. Stylistics. Pragmatics.

Hace más de un siglo que Ramón López Velarde consignó en su crónica titulada "Poesía y estética" el asombro de aquel día de 1914 en que visitó, junto a Jesús Villalpando, a José Juan Tablada en su residencia de estilo japonés: “Nos recitó en su jardín”, dice el poeta zacatecano, "en presencia de los sapos y las otras bestias predilectas los poemas en los que los alaba" (Velarde, 1990, p. 359). López Velarde afirma que fue "un bello día", con lo que profetiza hasta cierto punto el título que recibirán aquellos poemas al ser publicados, años más tarde. José Juan Tablada era afecto de trasplantar objetos, costumbres, seres y hasta personas japonesas hasta su residencia de ensueño. Sin embargo, el ambiente de aquel "bello día", nos cuenta el autor de La suave patria, se vio ensombrecido: "un criado japonés avisó en japonés la muerte de unos pájaros japoneses, por brusquedad del clima del Valle. Aquel dolor antípoda no dejó de ensombrecernos. Pero fue momentáneo" (Velarde, 1990, p. 359). Como aquellos pájaros, José Juan Tablada también había decidido adoptar una forma poética extranjera, el haikai, y verterla al español. No obstante, la suerte que aquellos poemas, aquellas "mariposas de instantes", como dijera Tablada, correrían bajo la "brusquedad del clima del Valle" sería mucho menos fútil y tendría profundas repercusiones en las siguientes generaciones de poetas. 
En el presente trabajo se estudiarán dos aspectos de la síntesis poética en los textos brevísimos de José Juan Tablada desde una aproximación estilístico-pragmática basada en la Teoría de la Relevancia. Estos dos aspectos son los estilos maximalista y minimalista, que son las dos tendencias de la poesía de Tablada hacia lo discursivo y epigramático, por un lado, y hacia lo intuitivo por el otro. Para caracterizar estos dos estilos se tomarán dos poemas de cada tipo de los libros Un día... (1919) y El jarro de flores (1922). Antes, sin embargo, es necesario caracterizar las nociones de "poema sintético" como manifestación textual y "síntesis poética" como fenómeno estético. En ambos casos se recurrirá a la revisión de la tradición crítica en torno a los poemas breves de Tablada, así como a las afirmaciones realizadas por el poeta mismo en su prosa.

\section{Los "poemas sintéticos"}

Hace 100 años, en 1919, el poeta mexicano José Juan Tablada (1871-1945) publicó en Caracas, Venezuela, un libro inusual por su contenido. Se trataba de una antología de 38 poemas brevísimos cuyo tema eran impresiones del paisaje, los objetos cotidianos y la naturaleza, ninguno de ellos más extenso que cuatro versos de arte menor y en algunos casos acompañados con dibujos hechos por el propio autor. El libro se tituló Un día... Poemas sintéticos y constituyó el primer poemario inspirado por el haikai japonés en lengua española. El mote de "poemas sintéticos", más que un simple subtítulo constituyó una declaración de principios estéticos por parte de Tablada. Como él mismo apuntaría después, en ese momento su preocupación era la "síntesis", puesto que tenía la creencia de que "sintetizando" era la única vía para "expresar la vida moderna en su dinamismo y en su multiplicidad" (Tablada, 2007, 159). El mexicano también entendía este gesto como una renuncia a gran parte de sus pretensiones estéticas anteriores, pues consideraba que "para subir más, en llegando a ciertas regiones, hay que arrojar lastre" (Tablada, 2007, 160). Por lastre sin duda se refiere a lo que él llama la "zarrapastrosa retórica" en que había derivado la poesía modernista a principios del siglo XX. 
La relación de los poemas breves de José Juan Tablada con sus fuentes japonesas palidece ante los hallazgos de los estudios comparativos como los de John Page (1963), Atsuko Tanabe (1981) y Seiko Ota (2014) de los que se hablará más adelante. Sin embargo, queda pendiente caracterizar el fenómeno que en la poética del mexicano se adscribe a lo que Samuel Gordon llamó "estéticas de la brevedad" (Gordon, 2003). Este fenómeno fue nombrado por el propio poeta como "síntesis poética". En el presente trabajo se estudiará dicho fenómeno y por ese motivo se eligió llamarlos "poemas sintéticos" en tanto manifestaciones de la síntesis poética. Por consecuencia, se evita nombrar los poemas breves como haiku, haikai, jaikai, para favorecer un término que permita dar cuenta tanto de las características estilísticas de los textos como de su singularidad dentro de la poesía mexicana.

El prólogo a El jarro de flores junto con la conocida epístola de Tablada a Ramón López Velarde, su colega y amigo, en torno al libro Li-Po y otros poemas (1920) son documentos que dan fe de la perplejidad del autor de El florilegio ante la incomprensión con que fueron recibidas sus obras de este periodo. En ambos sitios insiste en su preocupación por la "síntesis poética". Ni López Velarde, ni Genaro Estrada, ni Enrique González Martínez captaron las alusiones a la tradición poética del Lejano Oriente de las cuales abrevaban no sólo la llamada "nueva lírica" de Tablada sino también sus "nuevas ideas estéticas". Sus contemporáneos valoraron antes que nada la actualidad del poeta coyoacanense, "su facilidad de adaptarse a cualquier forma extraña" (González Martínez, 2002, p. 369) así como "sus capacidades de renovación y su sed de novedad" (Estrada, 1983, p. 335) y lo consideran como "ave del paraíso" (López Velarde, 1990, p. 550), considerando sus nuevas ideas estéticas como un gesto emanado del exotismo propio del Modernismo.

La introducción de los poemas sintéticos, esos poemas "a la manera de los haikai japoneses" a la lírica mexicana significó la apertura de nuestra tradición hacia nuevas rutas de expresión donde se favoreciera lo intenso por sobre de lo extenso y lo sintético por encima de lo discursivo y explicativo, tal como el propio Tablada intuía. Los poetas de la generación inmediatamente posterior como Francisco Monterde, José Rubén Romero, Rafael Lozano, Jaime Torres Bodet, José 
María González de Mendoza y Carlos Gutiérrez Cruz (Arellano, 2010, p. 5) escribieron libros inspirados en la poesía japonesa tal como los de Tablada. Sin embargo, fue Octavio Paz quien, décadas más tarde, revaloró las aportaciones estéticas del coyoacanense a la literatura mexicana. Las reflexiones de Paz en torno a las virtudes y defectos de la poesía tabladiana tienen eco en la tradición crítica hasta la actualidad. A partir de Paz, queda abierta la pregunta por la relación de Tablada con sus fuentes asiáticas. Desde los trabajos pioneros dentro de la Academia, como los de John Page (1963) y Atsuko Tanabe (1981) se pone en evidencia que el poeta mexicano sólo pudo haber tenido acceso a la literatura japonesa y china por medio de estudios y traducciones europeas como las de Basil Hall Chamberlain, Michel Revon y Paul-Louis Couchoud.

La valoración que se hace del legado de los poemas sintéticos de Tablada a nuestra literatura se complejiza a partir de estos hallazgos filológicos y toma, al menos, dos vertientes: la primera representada por académicos como Page (1963) y más recientemente Seiko Ota (2014) que desde los estudios comparados entienden que a pesar de los esfuerzos de Tablada por imitar la poesía japonesa, el resultado es algo más bien propio del poeta mexicano. En algunos casos, Page llega a afirmar que los poemas sintéticos son "metáforas ingeniosas, pero no haiku, y dudosamente, vivencias poéticas" (Page, 1992, p. 512). Decir que estos poemas no son "vivencias poéticas" no quiere decir que Page demerite la poesía del coyoacanense; más bien quiere decir que en ella no es posible captar el tipo de vivencia poética que sí comunica el haiku japonés tal como él lo entiende. Este autor considera que poemas como los de Un día... están más influidos por el epigrama que por el haiku japonés. Con fundamentos comparatísticos sólidos, Page le da la razón a aquellos primeros críticos que de manera intuitiva asociaron la poesía de Tablada con el epigrama tradicional y contra los que Tablada se defiende en el prólogo a El jarro de flores.

La otra vertiente de estudios tabladianos, donde podemos colocar trabajos como los de Cantella (1979), Tanabe (1981), Galván (1983), Hernández Palacios (1991) y Valdés (1991), tienden a coincidir con Page en muchos aspectos -sobre todo en la cuestión de las fuentes- pero divergen en el matiz con el que se interpretan los resultados de la "adaptación" que Tablada hizo de la poesía 
japonesa al español. Para estos autores, los poemas sintéticos logran captar ciertos aspectos del haiku japonés como su capacidad de condensación y su poder de sugerencia de una imagen instantánea. Tanto Tanabe (1981) como Hernández (1991) y Valdés (1991) insisten en que Tablada era consciente de la imposibilidad de traducir de manera exacta las formas japonesas al español y que como consecuencia realizó una adaptación más que una imitación.

\section{2. ¿Qué es "síntesis poética"?}

La respuesta epistolar de José Juan Tablada a Ramón López Velarde es sin duda alguna uno de los documentos más valiosos para conocer, de viva voz, las ideas estéticas a las que el autor de EI florilegio se adscribía a finales de la década de 1910. Tanto Cantella (1979) como Renaldi (1979) nos hablan de la trascendencia de los libros publicados por Tablada en ese periodo como indicadores del tránsito estético desde el Modernismo hacia la Vanguardia. Pero si Renaldi encuentra que en poemas como "Nocturno alterno" o "El loro" aún incorporaba imágenes vanguardistas en formas modernistas, es posible afirmar también que ocurre también lo opuesto: los poemas brevísimos de Un día... y El jarro de flores así como en los ideográficos de Li-Po y otros poemas pueden considerarse formas innovadoras dentro de la lírica mexicana. Sin embargo, en ellos palpita una inquietud tan modernista como es la búsqueda de la "poesía pura" y Tablada introduce la síntesis en su poética como una nueva estrategia para alcanzarla. Dice en su carta a López Velarde que en sus poemas ideográficos (que son el tema a discusión) "todo es sintético, discontinuo y por lo tanto dinámico; lo explicativo y lo retórico están eliminados para siempre; es una sucesión de estados sustantivos; creo que es poesía pura" (Tablada, 2007, p. 160). Cabe señalar que dichos "estados sustantivos" no son otra cosa que las imágenes desplegadas por el poema en forma de estímulo visual (en los poemas ideográficos) o en forma de representaciones mentales (en los poemas 
sintéticos) $)^{1}$. Con la eliminación de "lo explicativo", el poema depende de su capacidad para sugerir lo no dicho. La brevedad trabaja en conjunto con la imagen para generar un efecto determinado.

Al hablar de poesía pura "como lo quería Mallarmé" (Tablada, 2007, p. 160), Tablada se refiere a la búsqueda del poeta francés por hacer volver al poema a su voz "órfica" primigenia, aquella de la que fue privado después de la "gran desviación homérica" ${ }^{2}$. Sin embargo, la estrategia del mexicano es radicalmente distinta a la del francés: donde Mallarmé lleva el lenguaje hacia sus límites a través de una prolija transformación de la sintaxis y la desnaturalización de la puesta en página, Tablada lo hace a través de la reducción de la imagen poética a su mínima expresión. El poeta mexicano concibe lo explicativo con relación al análisis, mientras que lo intuitivo de la poesía lo asocia con la síntesis ${ }^{3}$. En su poética existe una tensión latente entre su gusto por la revelación, la sorpresa y el humor, por un lado, y su preocupación por recuperar el carácter órfico de la poesía tal como la concebía Mallarmé, por el otro. En los dos estilos que toma su poesía breve sale a flote esta tensión: alcanzar la síntesis por la vía homérica de la metáfora que revela o por la vía órfica de la imagen diáfana que, sin embargo, oculta.

Hasta aquí se dijo que la síntesis implica el trabajo de una forma breve, despojada de "lo discursivo", que a su vez posibilita el despliegue de una o varias imágenes. Pero resta un elemento: la significación. ¿Cómo se interpreta esta imagen representada a través de una forma breve?

\footnotetext{
${ }^{1}$ Las ideas que Tablada expone en su carta a López Velarde son aplicables tanto a los poemas ideográficos, que originan la discusión, como a los poemas sintéticos. Como afirma el propio Tablada: "El carácter ideográfico es circunstancial, los caracteres generales son más bien la síntesis sugestiva de temas líricos puros y discontinuos, y una relación más enérgica de acciones y reacciones entre el poeta y las causas de emoción", y luego lo invita a leer sus libros Un día... y LiPo, los cuales "explicarán mis propósitos mejor que esta exégesis prematura" (Tablada, 2007, p. 160).

2 En un diálogo con Elémir Bourges consignado por Henri Mondor, Mallarmé afirma que: "La poesía se ha apartado enteramente de su camino después de la gran desviación homérica", a lo que Bourges responde: "¿Y antes de Homero, qué?", "Orfeo" contesta Mallarmé (Mondor, 1941, p. 683). La relación entre el orfismo de Mallarmé y el "haikai" japonés es propuesta por Paul-Louis Couchoud, a quien Michele Pascucci considera una de las principales fuentes detrás de las ideas estéticas de Tablada (Pascucci, 2013). Couchoud considera que los "epigramas líricos" japoneses (como él llama a los haikai) son la respuesta que Mallarmé buscaba como un retorno hacia el momento órfico de la poesía, anterior a lo discursivo del "momento homérico". Para Tablada, la literatura se divide en dos ejes: analítico-discursivo y sintético-intuitivo, donde el primero correspondería al eje mallarmeano de lo homérico y el segundo al eje de lo órfico.

3 "Exprésase en poesía, sobre todo en poesía moderna, lo inexpresable en prosa. La poesía es quintaesencia, espíritu, síntesis [...] La prosa es análisis inductivo o deductivo [...] La poesía es intuición pura" (Tablada, 1997, p. 137).
} 
Tablada nos dice que la síntesis se caracteriza por una "relación más enérgica de acciones y reacciones entre el poeta y las causas de emoción" (Tablada, 2007, p. 160). Lo dicho implica que el poema manifiesta la relación de acción y reacción ante las causas de emoción que generan estados sustantivos en el poeta. Como se verá en el análisis de los textos, el lector, por su parte, participa del poema como receptor del espectáculo del asombro del poeta ante lo representado o bien como espectador de la causa de emoción que el poeta le muestra con el menor grado de mediación posible.

Ahora bien, antes de proceder al estudio de los textos es indispensable construir un modelo de análisis que pueda dar cuenta de los tres aspectos de la síntesis tratados aquí: 1) las causas de emoción ("acciones"); 2) los estados sustantivos que son su efecto ("reacciones"); y, 3) la forma que permite manifestar la relación entre causas y efectos. Se trata de dar cuenta de una forma breve que al generar una serie de sugerencias en el lector genera un efecto de sorpresa. En pocas palabras, es necesaria una explicación de la síntesis poética en tanto trabajo entre brevedad, imagen y unidad.

El problema de la síntesis poética puede ser descrito en términos de las causas y los efectos de significado de las formas poéticas. En el caso particular de los poemas sintéticos Tablada, este fenómeno consiste en la relación entre forma breve, sugerencia y efecto de sorpresa. La brevedad del poema no sólo lo faculta sino también lo obliga a extraer su significación de lo sugerido, es decir, de lo implícito y lo no dicho. Pero los poemas sintéticos de Tablada no se detienen en la sugerencia sino que además se conforman para generar un efecto de sorpresa en el lector. La síntesis es brevedad en la forma, imagen en la causa del sentido y también unidad en el efecto de este sentido en el lector.

\section{La síntesis como estilo y metarrepresentación}

El modelo explicativo del presente trabajo se basa en las nociones estilístico-pragmáticas que la Teoría de la Relevancia propone para la comunicación literaria. En primer lugar, se eligió un modelo 
estilístico-pragmático porque en éste se conjuntan los aspectos principales intuidos por Tablada en su propia definición de la síntesis poética. Del lado estilístico es posible hablar de esquemas comunicativos que proponen una representación de un objeto (una causa de emoción) y que ponen de manifiesto una actitud para interpretarlo. Hay un poema breve que representa una imagen y que la interpreta en el modo de representarla. En segundo lugar, se eligió el modelo estilísticopragmático propuesto por la Teoría de la Relevancia dado que a partir de su concepción de la comunicación es posible hablar de las dos tendencias que se presentan en los poemas sintéticos de Tablada: una maximalista, con una actitud manifiesta a metaforizar lo representado; y otra minimalista, con una actitud mínimamente manifiesta hacia lo representado.

La aproximación del presente trabajo es estilística en tanto estudio de cierto tipo de construcciones lingüísticas que representan objetos a la vez que expresan determinadas actitudes a través del modo en cómo representan; es pragmática en el sentido en que, para caracterizar estas actitudes, se toman en cuenta aspectos comunicativos que van más allá de lo lingüístico y que conciernen a la relación entre enunciado, interpretación, actitud manifestada por el emisor y efectos comunicados al lector. Todo esto unificado bajo la concepción ostensivo-inferencial de la teoría pragmática de la Relevancia ${ }^{4}$, que concibe las funciones primarias del lenguaje y la comunicación de manera separada. El primero como una herramienta de procesamiento y conservación de información; la segunda como una facultad desarrollada por el ser humano para su supervivencia. Para esta teoría, la comunicación por medio del lenguaje es la más eficiente, aunque la relación entre ambos sea más bien contingente (Sperber y Wilson, 1995, p. 172-175).

La teoría pragmática de la Relevancia (TR) parte de una perspectiva psicolingüística, por lo tanto, considera que la comunicación humana no se lleva a cabo por medio de signos sino de formas lógicas que son metarrepresentaciones, es decir, representaciones de representaciones

\footnotetext{
${ }^{4}$ La Teoría de la Relevancia fue propuesta por Dan Sperber y Deirdre Wilson en la década de 1990 como respuesta a la teoría pragmática de Paul Grice aplicada a la "lógica conversacional". La TR es un desarrollo y perfeccionamiento de las ideas de Grice ya no sólo con relación a los intercambios verbales particulares sino a todos los procesos de comunicación verbal. Sperber y Wilson retoman una de las famosas "máximas" de Grice que reza "Sea relevante" (Grice, 1991, p. 27) y la convierten en el principio rector de su teoría cognitivo-comunicativa.
} 
mentales del interlocutor (Sperber y Wilson, 1995, p. 232). Esta representación de un pensamiento que se intenta comunicar se llama "forma proposicional". El enunciado, a su vez, es un esfuerzo por parte de un emisor por hacer que su interlocutor pueda llevar a cabo dicha metarrepresentación ${ }^{5}$. Al decir algo, el emisor modifica el entorno físico del destinatario con el fin de que éste sepa que intenta comunicarle algo, pero también para proporcionarle elementos que le permitan inferir la forma proposicional de su enunciado de la manera más económica. Esta forma proposicional no sólo expresa la intención del emisor (lo que quiso decir), sino también la actitud que éste manifiesta hacia lo que quiso decir (Sperber y Wilson, 1995, p. 80). El principio según el cual el destinatario puede hallar la interpretación correcta del enunciado del emisor es uno de economía cognitiva: se trata de la interpretación que proporcione la mayor cantidad de información de interés por el menor esfuerzo cognitivo de procesamiento (Sperber y Wilson, 1995, p. 123-132). Dicha interpretación es la más relevante y el proceso para alcanzarla es el "principio de relevancia" que sirve como fundamento de toda la TR.

El proceso de inferencia que el destinatario necesita seguir para recuperar el pensamiento representado que el emisor intenta comunicarle se basa en la recuperación de una serie de supuestos, que no son más que los "pensamientos que un individuo trata como representaciones del mundo real" y en oposición a "ficciones, deseos o representaciones de representaciones" (Sperber y Wilson, 1995, p. 2). Como puede verse, no se comunican ideas o significados, sino únicamente creencias. Es por ello que la lógica de esta teoría tiene que ser, necesariamente, no demostrativa, puesto que no caracteriza el lenguaje con base en su verificabilidad sino con relación a las hipótesis de interpretación que pueden ser más o menos plausibles según cierta situación.

Los supuestos que se desarrollan a partir de la información lingüística codificada por un enunciado son más fáciles de inferir y por lo tanto son más fuertes en términos de relevancia; los

\footnotetext{
${ }^{5}$ Los autores de la TR definen al enunciado de una manera amplia como "una modificación perceptible del entorno físico" (Sperber y Wilson, 1995, p. 196). Esto permite abarcar no sólo los enunciados construidos con elementos lingüísticos como palabras y frases, sino cualquier tipo de conducta ostensiva que tenga como fin poner de manifiesto un conjunto de supuestos que permitan al destinatario extraer la forma proposicional relevante para esa situación comunicativa.
} 
que se infieren con base en información contextual y esquemas lógicos previamente almacenados en la memoria cognitiva son más laboriosos en su recuperación y por lo tanto se les considera más débiles. A los primeros se les llama explicaturas y a los segundos implicaturas.

Tanto Adrian Pilkington (2000) como Deidre Wilson (2011) ponen énfasis en la aplicabilidad de la TR en el campo de la comunicación literaria. Afirma Wilson que:

Literary texts, like ordinary everyday utterances, are full of lexical and syntactic ambiguities, referential and lexical indeterminacies, unarticulated constituents, loose, hyperbolic or metaphorical uses of language, ironies, witticisms and indications of attitude. Both literary texts and ordinary utterances must be treated as pieces of evidence about the communicator's intentions, and interpreted in a context which is not fixed in advance but constructed as part of the interpretation process [Los textos literarios, al igual que los enunciados ordinarios de la vida diaria, están llenos de ambigüedades léxicas y sintácticas, indeterminaciones referenciales y léxicas, componentes inarticulados, usos vagos, hiperbólicos o metafóricos del lenguaje, ironías, giros ingeniosos e indicaciones de actitud. Tanto los textos literarios como los enunciados ordinarios deben ser tratados como piezas de evidencia sobre las intenciones de quien comunica, e interpretados en un contexto que no es fijado de antemano sino construido como parte del proceso de interpretación] (Wilson, 2011, p. 72)

El marco conceptual de la TR permitiría, si Wilson tiene razón, dar cuenta de la comunicación literaria con base en los mismos principios fundamentales propuestos para explicar el resto de la comunicación humana. Uno de los aspectos más interesantes en términos de esta aproximación pragmática hacia la literatura es la noción de estilo, revisada por María Victoria Escandell Vidal a partir de la propuesta planteada por Sperber y Wilson (1995, p. 202-224). Dependiendo de los fines del emisor, éste dota a su enunciado de un determinado estilo. El estilo es una consecuencia de la "adecuación" del enunciado al destinatario, es decir, "es el reflejo de la idea del emisor sobre las posibilidades inferenciales del destinatario" (Escandell, 1994, p. 56). En el caso de la comunicación 
literaria, esta adecuación es menos precisa que en la comunicación verbal. Sin embargo, la forma en que el texto literario se presenta pone de manifiesto actitudes hacia lo representado. Además, en la literatura el estilo puede variar según importancia que se ponga en que la atención del lector se centre en un conjunto bien delimitado de supuestos fuertes o en un conjunto amplio y más bien impredecible de significaciones y actitudes sugeridas. El primer caso podría corresponder, por ejemplo, a la literatura panfletaria con fines ideológicos bien determinados; el segundo, a la poesía simbolista.

La noción de estilo es fundamental para caracterizar la síntesis poética en términos pragmáticos, puesto que en la poesía los esquemas de verso son el punto de partida para manifestar actitudes y generar efectos estéticos en el lector. En este trabajo se estudiarán los dos estilos que manifiestan las dos concepciones estéticas se hallan en tensión dentro de la poesía de Tablada: lo homérico-discursivo y lo órfico-intuitivo. Al primero lo llamaremos de "estilo maximalista" en donde el texto funciona con base en metáforas y ostenta una actitud proposicional hacia la redescripción de los conceptos unificados metafóricamente; la otra la llamaremos "estilo minimalista" y en él el texto funciona con base en una descripción literal (una imagen) que alcanza su relevancia con base en el reconocimiento de una actitud proposicional muy débil. En términos de la Teoría de la Relevancia, se propondrá una explicación sobre el favorecimiento del estilo maximalista por encima del minimalista en la poética de Tablada ${ }^{6}$.

Se ha dicho que la síntesis poética consiste en el trabajo de la brevedad, la imagen y la unidad para la construcción de sentido. En términos más precisos, se dirá que lo que llamamos síntesis poética es un tipo de enunciado breve donde se construye una imagen de manera metafórica o literal y cuya relevancia se alcanza en la manifestación de una actitud proposicional del modo de representar ante lo representado. Los dos estilos a los que nos referimos aquí se explican

\footnotetext{
${ }^{6}$ La distinción maximalista/minimalista se retoma de Kyoko Arai (2013) quien la emplea para caracterizar en términos de la TR los grados de manifestación de los elementos implícitos de los haiku japoneses en su lengua original a la hora de ser traducidos en las lenguas occidentales. En este caso, las traducciones maximalistas son las que tienden a ser más explicativas (y por lo tanto más alejadas de la forma japonesa), mientras que las traducciones minimalistas son más sugerentes (y por ello las considera más fieles).
} 
en términos del tipo de relación que entablan estos tres aspectos: en el estilo minimalista el enunciado poético breve alcanza su relevancia a partir de una serie de implicaturas débiles que a su vez manifiestan una actitud proposicional débil. El énfasis del poema breve se pone en la imagen más que en la unidad. En el estilo maximalista, el enunciado poético alcanza su relevancia a partir de una o varias metáforas que manifiestan una actitud proposicional específica: el poema intenta redescribir los conceptos unificados en la imagen metafórica. El efecto que se genera a partir del reconocimiento de esta actitud es el de sorpresa. Los poemas de estilo minimalista se asemejan más al haiku y en ellos se pueden encontrar aspectos de la "vestidura invisible" que poseen dichos poemas de acuerdo con Tanabe (1991, p. 79). Los poemas de estilo maximalista, por otro lado, se parecen más a la lectura que Tablada hace del haikai a través del concepto de "epigrama lírico" de Paul-Louis Couchoud (Couchoud, 1921, citado en Pascucci, 2013, p. 487). Es por ello que dichos poemas vuelven explícita su actitud proposicional, lo cual sin duda corresponde a la idea de “vestidura visible" propia de la poesía occidental, en términos de Tanabe.

\subsection{El estilo maximalista}

Para ilustrar las características de los estilos maximalista y minimalista en los poemas sintéticos de Tablada se analizarán cuatro textos muestra, dos de cada tipo, los cuales serán tomados de Un día... y El jarro de flores. El primero de ellos se titula "La pajarera" y es el primero de la sección "La mañana" de Un día:

\section{Distintos cantos a la vez: \\ la pajarera musical \\ es una Torre de Babel. \\ (Tablada, 1991, p. 369)}

Para que el enunciado poético alcance su relevancia es necesario interpretar la relación entre los dos conceptos que conforman la imagen. En este poema, el sintagma de "la pajarera musical" es representado de manera metafórica a través del concepto "una Torre de Babel". Pero para 
comprender la relación icónica entre conceptos, es decir, la comparación implícita que está sugerida por el uso del copulativo "es" es necesario remitirse al contenido lingüístico del primer verso, el cual se interpreta de manera literal. El destinatario se remite a su conocimiento enciclopédico del concepto "Torre de Babel" y puede extraer que la Torre de Babel era un lugar donde se hablaban distintas lenguas a la vez. La relación icónica entabla una correspondencia entre la multiplicidad de lenguas y la multiplicidad de cantos de aves. En el proceso de interpretación se lleva a cabo otro de estrechamiento del significado del concepto "Torre de Babel" para contener sólo aquella parte de éste que concierne a la multiplicidad de voces. Al reconocer la semejanza, se alcanza la relevancia de la frase metafórica que compara a la pajarera con la Torre de Babel, pero aún no la del conjunto del enunciado poético.

Para que el enunciado poético alcance su relevancia es necesario extraer los supuestos implicados por la comparación entre el significado heurístico de "Torre de Babel" expresado por la metáfora y el contenido explícito del enunciado. Por ejemplo, una de estas implicaturas sería que el poema sugiere una analogía entre la voz humana y el canto de los pájaros o también que permite pensar la confusión de lenguas en la Torre de Babel como los cantos de pájaros que se superponen entre sí y se vuelven ininteligibles. La comparación entre lengua humana y canto de pájaro se refuerza si se atiende al contexto del poema: el texto va acompañado de un dibujo de Tablada donde aparecen distintas especies de pájaros. Esto añade un nivel nuevo de interpretación que quizá no modifique mucho el sentido metafórico pero que sí proporciona fuerza a la comparación lengua humana/canto de pájaro. Así como las lenguas diferencian a los distintos conjuntos de individuos, asimismo los cantos diferencian a las distintas especies de aves.

La función del verbo "es" del último verso es lo que Kyoko Arai llama "elipsis poética" (Arai, 2013, p. 65): este verbo tiene implícita entre sus funciones gramaticales la de introducir una comparación y con ella la actitud proposicional con la que será metarrepresentado el concepto de “pajarera musical”. En términos de Paul Ricœur (2001), la metarrepresentación metafórica funciona 
como un esquema para ver algo como otra $\operatorname{cosa}^{7}$. El poema nos hace ver a la pajarera como una Torre de Babel. Al hacernos construir una imagen que revela semejanzas entre dos elementos en principio tan disímiles, el poema de Tablada cumple con el trabajo de la síntesis poética: en la brevedad de tres versos nos sugiere la imagen de una pajarera que semeja una Torre de Babel, pero al redescribir la pajarera también nos permite redescribir el concepto de Torre de Babel a través de la comparación entre la multiplicidad de voces humanas y la multiplicidad de "voces" de aves. Si estas últimas se confunden de manera "musical" (como se nos dice en el poema), ¿acaso no podemos pensar que tal vez la confusión de lenguas en la Torre de Babel también tenía su propia armonía musical? El trabajo de la unidad está detrás de esta redescripción de los dos conceptos comparados. Después de pensar de manera nueva la relación entre multiplicidad de voces y musicalidad, el contenido tanto del concepto de pajarera como el de Torre de Babel quedará modificado. El poema propone de manera implícita la metarrepresentación propia de la metáfora como un modo de redescribir las imágenes presentadas. El poema no alcanza su relevancia con base en una sola implicatura fuerte (por ejemplo, el reconocimiento de las semejanzas entre los conceptos presentados) sino que lo hace a partir del reconocimiento del despliegue de una amplia gama de implicaturas débiles.

Esta aproximación a la síntesis poética será favorecida por Tablada por encima del estilo minimalista. Los poemas sintéticos de El jarro de flores, los cuales reciben el mote de "disociaciones líricas", presentan en su mayoría una estructura maximalista en donde se pone de manifiesto la actitud proposicional del texto poético: al unificar varios elementos en una sola imagen se pretende incidir sobre la información que el lector tiene sobre dichos elementos. La síntesis se encuentra en el reconocimiento de esta transformación mutua que da lugar a nueva información. El poema, por su parte, se convierte en el esquema que la vuelve posible.

\footnotetext{
${ }^{7}$ En La métaphore vive afirma Ricœur [la traducción es nuestra]: "El ver-como juega de manera muy exacta el rol del esquema que une el concepto vacío y la impresión ciega [énfasis del autor]; por su carácter de semipensamiento y semiexperiencia, junta la luz del sentido con la plenitud de la imagen. Lo no verbal y lo verbal son, así, unidos estrechamente en el seno de la función imaginativa del lenguaje" (Ricœur, 2001, p. 270).
} 
Esto se puede corroborar con el estudio de un segundo ejemplo de poema sintético de estilo maximalista, esta vez tomado de El jarro de flores:

Hotel "La Esperanza"

En un mar de esmeralda

buque inmóvil

con tu nombre por ancla.

(Bogotá, Colombia)

(Tablada, 1991, p. 425)

En este poema la imagen presentada en el espacio de los tres versos no es suficiente para construir una interpretación relevante. Se describe un objeto (un buque inmóvil) en un espacio (mar de esmeralda). El tercer verso construye una metáfora en donde se representa al "nombre" como "ancla". El lector podría gastar energías en buscar semejanzas entre los conceptos de "nombre" y "ancla". Sin embargo, con mucho menor esfuerzo puede construir una interpretación plausible al recurrir a los elementos del entorno: el título y hasta el lugar donde fue escrito. En el título encontramos el nombre propio de un lugar (un hotel) indicado por las comillas y el uso de las mayúsculas. Si "La Esperanza" es el "nombre" al que se alude en el poema, entonces la relación de metarrepresentación cambia: se intenta que el lector vea la esperanza como ancla. Es allí donde el lector infiere la relación de semejanza entre el ancla que es algo que inmoviliza los barcos con la esperanza que puede inmovilizar a quien espera. La frase metafórica alcanza su relevancia pero aún no el resto del enunciado: si "La Esperanza" es el referente del sintagma "tu nombre" entonces puede decirse que dicho nombre pertenece al "buque inmóvil" de la frase anterior. En este punto se entabla otro nivel de metáfora donde se representa al "hotel" como "buque inmóvil". El hotel es un inmueble y por lo tanto comparte con el buque la característica de ser inmóvil, aunque también, se puede implicar de manera más débil que comparten otras semejanzas: grandes dimensiones, ventanas, alojamientos, etc. Hasta aquí el poema nos presenta una metáfora compleja donde un hotel es un buque cuya ancla es su nombre, la esperanza. Pero eso no es todo, queda un tercer nivel 
de metarrepresentación: el mar de esmeralda donde se halla el hotel-barco anclado por la esperanza. Si se toma en cuenta que el lugar donde fue escrito el poema es Bogotá, Colombia, y el lector tiene la información suficiente para saber que Bogotá es una ciudad enclavada en las montañas, entonces surge un nuevo nivel metafórico en donde se entiende que el hotel no se encuentra en el mar sino en un espacio lleno del color esmeralda. Esto sugiere de manera débil que el hotel se encuentra en un área selvática o boscosa, llena de plantas de color esmeralda. Los elementos marinos (mar, buque, ancla) sirven para redescribir el paisaje de un hotel en Bogotá, pero a su vez, se nos descubren nuevas significaciones de los elementos marinos: el buque puede ser visto como un hotel móvil, el esmeralda del mar y el de la montaña se equiparán. Aunque las estrategias difieren, el esquema funciona igual: se representan unificados varios elementos para extraer del conjunto una serie de informaciones nuevas que los redescriben.

La actitud proposicional que ambos textos manifiestan con la redescripción de imágenes por medio de la metáfora es la de la sorpresa. Ese es el mood que sirve como forma proposicional del texto: la voz poética se sorprende ante la imagen descrita. En el momento en que el lector es capaz de recuperar esa sorpresa y compartir, aún de manera vaga, la actitud del emisor, entonces el texto alcanza su relevancia y consigue comunicar. Por supuesto que, como es de esperarse, esta comunicación es débil y se construye, en su mayoría, a partir de supuestos que inferidos del contexto y el bagaje enciclopédico del lector. Son un conjunto de implicaturas débiles que sugieren un mood, una actitud, y con ello ponen de manifiesto una impresión.

En la revisión de las tendencias críticas en torno a los poemas sintéticos realizada en el apartado 2 se habló de la asociación inmediata de los textos de Tablada con el género del "epigrama". Aunque en el prólogo a El jarro de flores (1922) el mexicano deslinda a sus creaciones ("el 'Haikai, de floral desnudez, no necesita búcaros", Tablada, 1992, p. 421), es verdad que su definición no dista mucho de la de este género poético: "Por esencia [el haikai] es justo vehículo del pensamiento moderno; tema lírico puro, adámico como la sorpresa y sabio como la ironía" 
(Tablada, 1991, p. 421) ${ }^{8}$. Tanto epigrama como haikai, al menos en términos de Tablada, comparten la brevedad y una actitud humorística. El mexicano interpreta este "tema lírico puro" como esencial para caracterizar el haikai, en que él se basa para escribir sus poemas sintéticos ("poemas al modo de los haikai o hokku", Tablada, 1992, p. 421). Las evidencias proporcionadas por Pascucci (2013) apuntan a que Tablada retoma gran parte de sus ideas sobre el haikai de la lectura de Paul-Louis Couchoud quien caracteriza a estos poemas japoneses con el nombre de "epigramas líricos". Los poemas de estilo maximalista de Tablada le deben más a la concepción de Couchoud, donde lo epigramático (humor, ironía y sorpresa) se une con lo lírico (una impresión, una emoción). Y aunque estos textos de estilo "homérico" (en términos mallarmeanos) constituyen casi una norma, es necesario revisar los poemas excepcionales en donde Tablada muestra una tendencia distinta: en vez de manifestar una actitud y comunicar una sorpresa, pareciera que en dichos poemas sólo se muestra una imagen sin ningún indicio de metarrepresentación, lo cual los vuelve enigmáticos.

\subsection{Estilo minimalista}

Para comenzar el estudio de los poemas sintéticos de estilo minimalista, se eligió un par de casos que aparecen en Un día... El primero de ellos se titula "Los zopilotes" y es el segundo texto de la sección "La mañana”:

$$
\begin{aligned}
& \text { Llovió toda la noche } \\
& \text { y no acaban de peinar sus plumas } \\
& \text { al sol, los zopilotes. }
\end{aligned}
$$

(Tablada, 1991, p. 369)

Este poema es de un tipo más descriptivo y por lo tanto se puede interpretar su contenido a partir de su explicatura, es decir, a partir de su contenido lingüístico. Sin embargo, presenta muchos

${ }^{8}$ Compárese esta definición con la entrada que el Diccionario General y Técnico Hispanoamericano de Manuel Rodríguez-Navas de 1918 registra para "epigrama": "Composición poética, breve y aguda, que encierra un pensamiento principal, casi siempre festivo y satírico" (Rodríguez-Navas, 1918, p. 705) 
problemas para interpretarlo en términos de su relevancia. Dado que en su explicatura no surgen el mismo tipo de discordancias semánticas y lógicas que en el caso de "La pajarera", su relevancia debe de hallarse implícita o relacionada con el contexto. A diferencia del matiz interesante que el dibujo que acompaña al caso anterior, en este poema nos hallamos un dibujo tan simple por lo tanto tan enigmático como el poema mismo. La forma del poema está dispuesta para que primero se presente una situación ambigua: hubo una lluvia y algún animal se peina las plumas. Enunciados de esta clase alcanzan su relevancia con base en implicaturas más débiles. Una de ellas podría derivarse de la discordancia entre los temas típicos de la forma poética elegida por Tablada como modelo, el haikai japonés, y el empleo en este caso de un animal típicamente mexicano. Además, podrían atenderse las metarrepresentaciones culturales que existen en torno al concepto de "zopilote", es decir, las actitudes proposicionales que la cultura mexicana manifiesta al representar a este animal. El zopilote es un animal carroñero y por lo tanto se asocia con la muerte. A partir de esta implicatura débil puede extraerse otra más, a partir de la cual se relaciona la ausencia de una actitud proposicional en el poema al representar al zopilote con el contexto del libro: en el apartado titulado "La mañana" los poemas tocan temas relacionados con animales, plantas o elementos del paisaje en un tono eufórico y contemplativo. Quizá la relevancia de este poema estriba en que también es posible representar de manera contemplativa (p. ej. en el acto de peinar sus plumas) a ciertos animales que son asociados con situaciones disfóricas o negativas como la muerte. Como es evidente, estas implicaturas débiles están más relacionadas con las conjeturas planteadas por quien lo interpreta y no alcanzan a sustentarse de manera firme en el texto poético.

Existe, sin embargo, otra conjetura que, a pesar de ser también una implicatura débil, podría ayudar a esclarecer la aparente irrelevancia de la imagen presentada. En este poema Tablada pone de relieve el aspecto de la "desnudez" del haikai, es decir, la ausencia lo explicativo y lo discursivo. El efecto que se genera es paradójico, puesto que una imagen bastante explícita se torna en enigma. El haikai y el haiku japonés, a diferencia de poemas de este tipo, alcanzan su relevancia sin presentar un enigma puesto que existen metarrepresentaciones culturales bastante difundidas en 
torno a los tópicos tratados: las imágenes aluden a estaciones del año y en síntesis sugieren emociones específicas que no se hallan explícitas en el contenido del texto. Además, existe una metarrepresentación cultural que reviste de una dimensión estética a los poemas breves japoneses: el mono no aware ${ }^{9}$, que no es otra cosa que el efecto emocional que lo efímero de las cosas del mundo provocan en quien las admira. Cuando un japonés lee un haiku o un haikai la actitud proposicional hacia lo representado que éste le intenta comunicar se vuelve manifiesta desde su bagaje cultural: la imagen desnuda es una ventana hacia la belleza efímera. En el caso de Tablada, en cambio, la búsqueda por desnudar la imagen sin manifestar una actitud sugiere otras nociones, más imprecisas, pero no por ello menos significativas en el terreno de la poesía: la impresión de lo "adámico", aquello que tiene que ver con la percepción de las cosas antes del lenguaje que en Mallarmé se asocia con lo "órfico".

Antes de entrar en detalle con lo antes dicho, hay que revisar el segundo ejemplo de este estilo minimalista que es el caso del poema titulado "Los sapos" recogido en el apartado “Crepúsculo" de Un día...:

Trozos de barro, por la senda en penumbra saltan los sapos.

(Tablada, 1991, p. 382)

Este poema es uno de los más reconociblemente "japoneses" de entre los que escribió Tablada. Se trata de una imagen de la naturaleza que por universal puede ser mexicana, japonesa o europea si se quiere. Se ha comparado muchas veces este poema con el celebérrimo Furuikeya del poeta japonés Matsuo Basho, uno de los exponentes del haikai más conocidos en occidente. El poema reza:

9 "Uno de los elementos fundamentales de la lírica japonesa es lo que se llama mono-no-aware, que se establece mediante la unión de emociones personales bajo una estructura de pensamiento impersonal... la traducción literal [...] sería: "sentimientos sobre las cosas" ... sentimientos inspirados por la belleza de algún fenómeno natural o por la bondad del corazón humano" (Tanabe, 1981, p. 55). 


\author{
Un viejo estanque. \\ Se zambulle una rana: \\ ruido del agua. \\ (trad. Antonio Cabezas, 2007, p. 33)
}

Igual que en el caso de "Los sapos" de Tablada, hay un lugar ("viejo estanque" y "camino en penumbras"), acción ("salto de rana" y "salto de sapos") y un efecto del movimiento sobre el lugar ("ruido de agua" y "trozos de barro"). La desnudez de la imagen del poema de Basho, al menos en la traducción, es tal que pareciera una ventana hacia la interioridad misma de las cosas. Para un japonés en su versión original, la rana tiene un significado relacionado con una estación del año; para el lector occidental, es una imagen que asombra por su sencilla desnudez. Si se considera que el esquema breve del texto sólo manifiesta una imagen explícita y una ausencia de metarrepresentaciones culturales en torno a ella, entonces su relevancia se alcanza con base en la impresión que generan en conjunto las implicaturas débiles que pueden derivarse. Es posible aventurar, con base en la evidencia indirecta proporcionada por el propio Tablada, que el significado de la aparente ausencia de actitud proposicional sea la de provocar el asombro original de la captación de las cosas de manera intuitiva, sin mediación del lenguaje. Esa impresión adánica es una de las grandes utopías de la poesía occidental y es el paraíso perdido, el momento órfico, al que la síntesis poética se propone recuperar. Por parte de Tablada recibió un nombre: "poesía pura". El poema de nuevo actúa de manera metafórica, aunque se trata de una metáfora mucho más rica, una metáfora viva en el sentido de Ricœur (2001) pues el poema hace ver al lector la imagen representada como si vista a través de la mirada utópica de Adán y Orfeo, antes del pecado original de lo discursivo y lo retórico. No se trata propiciar un encuentro auténtico (y por demás imposible) entre sujeto y objeto, sino utilizar el lenguaje para evocar el no-lenguaje. Hace que en su unidad, el lenguaje actúe como no lenguaje, como instancia nouménica y genere en el lector el efecto de asombro de hallarse ante la mirada original del primero de los poetas del mundo. 


\section{Conclusión}

La síntesis poética siguió dos derroteros en la obra de Tablada. Uno de ellos prolijo y afín con la personalidad del poeta, que era afecto a la revelación, la sorpresa, el humor y la ironía. El segundo apareció en menor medida y reflejaba su inquietud estética más profunda, derivada de su profunda admiración por la poesía de Mallarmé y las ideas de Charles Baudelaire. Con base en las evidencias del análisis puede afirmarse que los motivos del favorecimiento de uno por encima del otro fueron económicos en términos de esfuerzo: para los lectores y para el propio Tablada era mucho más sencillo extraer efectos poéticos de los poemas de estilo maximalista, ricos en imágenes, sorpresa y humor; por otra parte, los de estilo minimalista requieren de un esfuerzo mucho mayor, aunque las implicaciones de su belleza no desmerecen. Pero Tablada, a diferencia de su admirado Mallarmé, no era un poeta hermético y más tarde, en La feria (1928), encontraría el modo de incorporar la poderosa capacidad de sugerencia de la síntesis poética en los poemas extensos y de ponerla al servicio de un conjunto de metarrepresentaciones culturales muy rico y recién descubierto por un Adán de la poesía mexicana como fue Ramón López Velarde (mote otorgado por Xavier Villaurrutia): el folklore mexicano. A la sazón de la reconstrucción nacional de los años veinte, la mirada adámica se ponía a trabajar para redescribir la circunstancia nacional. Además, el estilo maximalista fue el que moldearía la forma de expresarse de toda una tradición de haijines (creadores de haiku) mexicanos, como muestran sendos estudios por parte de Ceide Echavarría (1967) y más recientemente Arellano (2010). El estilo minimalista, por su parte, queda como testimonio de que Tablada pudo vislumbrar la cristalización del proyecto de Stéphane Mallarmé y Paul-Louis Couchoud quienes veían en las formas de expresión orientales la vía para recobrar el momento órfico a través de su unificación con lo homérico y lograr una síntesis histórica del devenir poético en donde por fin se lograría una inmediatez entre lector, poeta y objeto poético.

\section{Referencias:}


Arai, K. (2013). How Can We Translate Invisible Constituents in Haiku. Translation Ireland, 19 (1), 6576.

Arellano, D. (2010) Aproximación a la naturaleza del haiku mexicano (Tesis de licenciatura). México: UNAM.

Cabezas, A. (2007). Jaikus inmortales. Madrid: Hiperión.

Cantella, B. (1979, octubre-diciembre). Del modernismo a la vanguardia. Estética del haikú. Revista Iberoamericana, 639-649.

Ceide, G. (1967). El haikai en la lírica mexicana. México: Ediciones de Andrea.

Escandell, M. V. (1994). La noción de estilo en la Teoría de la Relevancia. En Elsa Dehennin y Henk Haverkate (Dir.), Lingüística y estilística de textos. Amsterdam: Rodopi, p. 55-64.

ESTRADA, G. (1983) Un raro de la literatura americana. Obras, México: FCE, p. 333-336.

Galván, D. (1983). José Juan Tablada y su haikú: aventura hacia la unidad. Cincinnati Romance Review, 2, 110-120.

González, E. (2002). La apacible locura. Obras 3, México: El Colegio Nacional.

Gordon, S. (2003). Estéticas de la brevedad. Revista Fractal, 3. Obtenido el 26 de septiembre de 2018 desde https://www.mxfractal.org/F30gordon.html

Grice, P. (1991). Logic and conversation. En Paul Grice, Studies in the Way of Words, Cambridge:

Harvard University Press, p. 1-144.

Hernández, E. (1991) José Juan Tablada: un infractor del hai-kai. Literatura mexicana, 1 (2), 393-420.

LÓPEZ VELARDE, R. (1990). Obras. México: FCE.

MONDOR, H. (1941). Vie de Mallarmé. París: Gallimard.

Ota, S. (2005). José Juan Tablada. La influencia del haikú japonés en “Un día...”. Literatura Mexicana, $16(1), 133-144$.

Ota, S. (2014). José Juan Tablada: su haikú y su japonismo. México: FCE. 
Page, J. (1963). José Juan Tablada, introductor de haikai en Hispanoamérica (Tesis doctoral). México: UNAM.

Page, J. (1992, septiembre-diciembre). José Juan Tablada y el anti-haiku. Estudios de Asia y África, $89(3), 509-512$.

Pascucci, M. (2013, septiembre). Las “fuentes chinas" de José Juan Tablada: revelación y reevaluación. Hispania, 93 (3), 481-492.

Paz, O. (1957). Estela de José Juan Tablada. Las peras del olmo. México: Imprenta Universitaria. Pilkington, A. (2000) Poetic Effects. Ámsterdam: John Benjamins.

Renaldi, T. W. (1979, enero-marzo). Imágenes vanguardistas entre formas modernistas. Texto Crítico, 5 (12), 253-260.

Ricœur, P. (2001). La metáfora viva. Madrid: Trotta.

Rodríguez-Navas, M. (1918). Diccionario general y técnico hispano-americano. Madrid: Cultura Hispanoamericana.

Sperber, D. y Wilson, D. (1995). Relevance. Communication and Cognition. Oxford: Blackwell.

Tablada, J. J. (1991). Obras I. Poesía. México: UNAM.

Tablada, J. J. (1997). La feria de la vida. México: Conaculta.

Tablada, J. J. (2007). De Coyoacán a la Quinta Avenida. México: FCE.

Tablada, J. J. (2008). Un día... Poemas sintéticos (edición facsimilar). México: Conaculta.

Tanabe, A. (1981). El japonismo de José Juan Tablada. México: UNAM.

Valdés, H. (1991). Prólogo. En José Juan Tablada. Obras I. Poesía. México: UNAM.

Wilson, D. (2011). Relevance and the Interpretation of Literary Works. UCLWPL, 1, 69-80. 